\title{
GmPRP2 promoter drives root-preferential expression in transgenic Arabidopsis and soybean hairy roots
}

Li Chen, Bingjun Jiang, Cunxiang Wu, Shi Sun, Wensheng Hou ${ }^{*}$ and Tianfu Han ${ }^{*}$

\begin{abstract}
Background: Promoters play important roles in gene expression and function. There are three basic types of promoters: constitutive, specific, and inducible. Constitutive promoters are widely used in genetic engineering, but these promoters have limitations. Inducible promoters are activated by specific inducers. Tissue-specific promoters are a type of specific promoters that drive gene expression in specific tissues or organs. Here, we cloned and characterized the GMPRP2 promoter from soybean. The expression pattern indicated that this promoter is root-preferential in transgenic Arabidopsis and the hairy roots of soybean. It can be used to improve the root resistance or tolerance to pathogens, pests, malnutrition and other abiotic stresses which cause extensive annual losses in soybean production.

Results: The GmPRP2 promoter (GmPRP2p-1062) was isolated from soybean cv. Williams 82. Sequence analysis revealed that this promoter contains many cis-acting elements, including root-specific motifs. The GmPRP2p-1062 and its 5'-deletion fragments were fused with the GUS reporter gene and introduced into Arabidopsis and the hairy roots of soybean to further determine promoter activity. Histochemical analysis in transgenic Arabidopsis showed that GUS activity was mainly detected in roots and hypocotyls in all deletion fragments except GmPRP2p-471 (a 5'-deletion fragment of GmPRP2p-1062 with 471 bp length). GUS activity was higher in transgenic Arabidopsis and hairy roots with GmPRP2p-1062 and GmPRP2p-852 (a 5'-deletion fragment of GmPRP2p-1062 with 852 bp length) constructs than the other two constructs. GUS activity was enhanced by $\mathrm{NaCl}, \mathrm{PEG}, \mathrm{IAA}$ and JM treatments and decreased by SA, ABA and GA treatments in transgenic Arabidopsis.

Conclusions: GmPRP2p-1062 is a root-preferential promoter, and its core fragment for root-preferential expression might lie between -369 and +1 . GmPRP2p-852 may be useful in the genetic engineering of novel soybean cultivars in the future.
\end{abstract}

Keywords: Soybean, PRP2, Promoter, Root-preferential, Arabidopsis thaliana, Deletion, GUS, Hairy root

\section{Background}

Promoters play a very important role in the initiation and regulation of gene transcription, and they are important components in transgenic engineering [1]. Promoters can be divided into three types: constitutive, specific, and inducible. Constitutive promoters are widely used in genetic engineering. The cauliflower mosaic virus (CaMV) $35 \mathrm{~S}$ promoter directs the expression of target genes in almost all tissues at all developmental stages [2]. However, the

\footnotetext{
*Correspondence: houwensheng@caas.cn; hantianfu@caas.cn MOA Key Laboratory of Soybean Biology (Beijing), Institute of Crop Sciences, The Chinese Academy of Agricultural Sciences, Beijing, China
}

constitutive expression of transgenes is not always desirable for research and application. Constitutive expression for research purposes would conceal the elaborate function of transgenes, especially in signal transduction, energy transformation, and material transportation. Constitutive expression for applied purposes may cause an extra metabolic burden or toxic effects in transgenic plants. The repetitive use of the same promoter in genetic transformation is one of the major reasons for transgenic silencing [3-5]. Therefore, the development of specific or inducible promoters is necessary.

Inducible promoters are often regulated by particular chemical and physical factors, such as light, wounding, 
temperature, $\mathrm{pH}$, hormones [6]. They can strongly enhance gene expression, and some of them are also specific [7].

Tissue-specific promoters are a type of specific promoters that drive gene expression within specific tissues or organs. Many specific promoters with different tissue specificities have been isolated and studied in transgenic research, including root-specific promoters [8-11], flower organ-specific promoters [12-15], seedspecific promoters [16,17], and fruit-specific promoters [18-20]. Hormones or abiotic stresses may regulate tissue-specific promoters. For example, wounds induce the rice $M T$ promoter, which is preferentially expressed in roots and flowers [21]. The root-specific promoter, PSPR10, expresses higher GUS in response to the abiotic stresses $\mathrm{NaCl}$, PEG6000 and mannitol as well as in response to SA, ABA and JA [9]. However, some tissuespecific promoters may have low activity or specificity, especially when these promoters drive gene expression in heterologous plants.

Soybeans are faced with severe root-related pathogens, pests, malnutrition and other abiotic stresses [22]. Soybean production suffers heavy losses from rootrelated biotic or abiotic stresses annually. For example, the soybean cyst nematode (Heterodera glycines Ichinohe) ( $\mathrm{SCN}$ ) was the primary cause for the suppression of soybean yield in the US from 2003 to 2005, and the yield suppression due to SCN in the US was approximately 8.3 million tons during these 3 years [23]. However, no efficient and economical methods have been developed to combat these diseases. Therefore, transgenic technology using root-specific promoters is promising because a transgenic soybean with a constitutive promoter has been successful worldwide [24].

Alfalfa $A$ 9, rice $R c c 2$ and $R c c 3$, carrot $P R P 1$, maize $Z R P 3$ and bean $P V R 5$, which all encode a proline-rich protein (PRP), are expressed preferentially in root [25-28]. Three members of the $P R P$ family are expressed in soybean with distinct, individual patterns of expression in different organs and at different development stages [29-31]. GmPRP1 and GmPRP2 exhibit root-specific expression [30,31]. Soybean PRP1 mRNA is highly abundant in the elongating and mature region of the hypocotyls epidermal cells of seedlings. Soybean PRP2 mRNA accumulates in phloem cells, and PRP3 mRNA is specifically localized to the endodermoid layer of cells in the hypocotyl-elongating region $[32,33]$. PRPs are expressed with spatiotemporal specificity $[34,35]$. Moreover, factors associated with biotic and abiotic stresses also influence the expression of PRPs [36-39].

Some genes encoding PRPs have been isolated from soybean, but the function of the PRP promoters is not well characterized. Here, we cloned the GmPRP2 promoter and studied its expression activity in transgenic Arabidopsis and soybean hairy roots.

\section{Results}

\section{Detection of GmPRP2 expression by quantitative} realtime PCR

GmPRP2 expression was investigated by real-time PCR from root, stem, leaf, flower, seed and hypocotyl. The expression level was highest in the root, and second in the hypocotyl, seed and stem. The level in the leaf and flower were much lower than in the root (Figure 1). Therefore, GmPRP2 gene showed a root-preferential expression.

\section{Cloning and sequence analysis of the GmPRP2 promoter (GmPRP2p-1062)}

A 1,236 bp 5' flanking region fragment of the PRP2 gene was amplified using first-round PCR. This fragment contained a 174 bp GmPRP2 gene partial coding sequence. The second PCR product contained a 1,062 bp flanking sequence upstream of the translated initiation codon. The first nucleotide of GmPRP2 cDNA was designated as +1 to orient the sequence numbers. The promoter sequence was analyzed using the PLACE and PlantCARE web tools. Several putative cis-regulatory elements were deciphered from the promoter sequence of GmPRP2 (Figure 2A). TATA box sequence elements, which were required for critical and precise transcription initiation, were found in the -317 region of the sequence. CAAT BOX sequences, which were responsible for the tissue-specific promoter activity, were found at numerous positions: $-776,-762$, $-449,-409,-347,-342,-227$, and -167 . OSE2ROOTNODULE sequences, which were responsible for an organ-specific promoter activity in infected cells of root nodules, were found at -1000 and -430 . ROOTMOTIFTAPOX1 sequence elements, which were required for organ specificity, were identified at the -251 position. OSE2ROOTNODULE elements and ROOTMOTIFTAPOX1 element are critical for root-specific expression.

Other important promoter elements and their putative functions are photographed (Figure 2A) and listed (Additional file 1). The ABRELATERD1 site at -12 and ACGTATERD1 site at -282 and -12 were responsible for dehydration. ARR1AT transcription factors for genes were located at $-1044,-955,-616,-542,-147$, and -93 . The copper- and oxygen-responsive element, CURECORECR, was found at the $-878,-617$, and -135 positions. GT1GMSCAM4 participated in pathogen- and salt- induced SCaM-4 gene expressions and presented at $-995,-628$, and -260 . MYB1AT and MYBCORE binding sites of MYB were found at $-392,-50,-731$, and -219. Hormone-responsive elements, T/GBOXATPIN2, involved in jasmonate signaling and WBOXNTERF3, involved in the activation of the ERF3 gene, were sited at -13 and -143 , respectively. Some lightresponsive transcription elements, such as EBOXBNNAPA $(-842,-326,-244,-167)$, GT1CONSENSUS $(-995,-850$, 


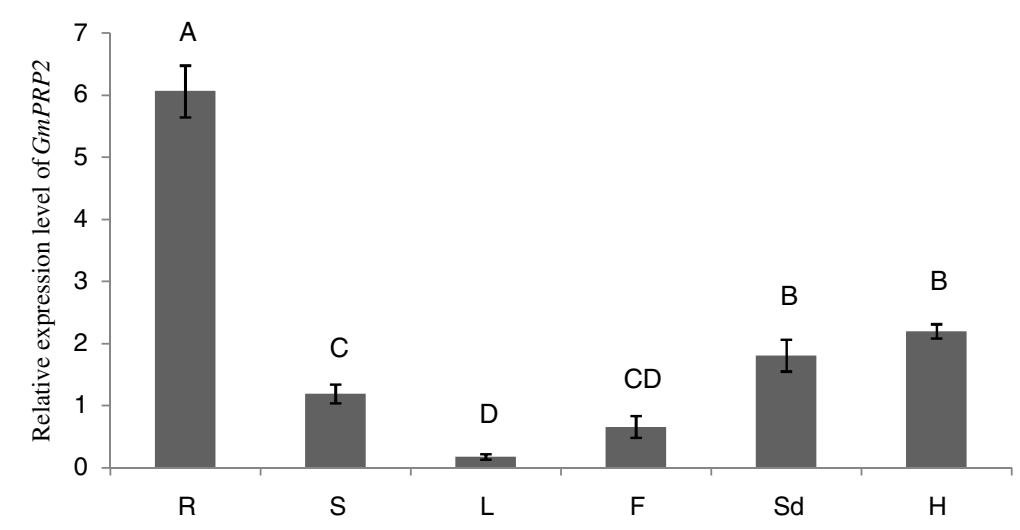

Figure 1 The expression level of GmPRP2 by qRT-PCR in different tissues. The relative expression level of GmPRP2 from real-time PCR was in different tissues. $\mathrm{R}$, root; $\mathrm{S}$, stem; L, leaf; $\mathrm{F}$, flower; $\mathrm{Sd}$, seed; $\mathrm{H}$, hypocotyl. Data are the means of three replicates with $\mathrm{SE}$ shown by vertical bars. The capitals differ significantly by one-sided paired $t$ test at $\mathrm{P}<0.01$.

$-628,-260,-162)$ and INRNTPSADB $(-778,-764)$, were also found in the promoter region.

Serial 5'-deletion fragments were created to identify the core region of the GmPRP2p-1062 that controlled tissuespecific expression: GmPRP2p-852, GmPRP2p-471 and GmPRP2p-369, which were 852, 471 and 369 bp in length, respectively, according to the density of the cis-elements on the promoter sequence (Figure 2B).

\section{Spatiotemporal expression patterns of GmPRP2p-1062 and the $5^{\prime}$-deletion fragments in Arabidopsis}

GmPRP2p-1062 driven GUS expression was monitored during plant development and in various organs using histochemical staining in $\mathrm{T}_{3}$ transgenic lines of Arabidopsis grown on $1 / 2$ MS medium to precisely define the spatiotemporal expression pattern of the GmPRP2 promoter. GUS expression was detected in hypocotyls and roots in 1day-old and 3-day-old seedlings carrying the GmPRP2p1062 construct, but GUS staining was not detected in the cotyledons and apical roots (Figure 3). GUS expression was detected strongly in roots of the 5-day-old and 7-day-old seedlings, but the staining was a little weak in the hypocotyls. GUS expression in 10-day-old and 20-day-old seedlings was similar to that of the younger seedlings.

The 5'-deletion fragments were also fused to the GUS gene and transformed into Arabidopsis. GUS staining showed that the GmPRP2p-852 and GmPRP2p-369 constructs presented similar expression patterns as the GmPRP2p-1062 construct, which was high in roots and hypocotyls, except leaves. GUS staining was not visible with the GmPRP2p-471 construct (Figure 3). Fluorometric GUS assays revealed that GmPRP2p-1062 and GmPRP2p-852 constructs drove strong GUS activity in roots, and GUS activity was significantly reduced in GmPRP2p-471 and GmPRP2p-369 constructs compared with GmPRP2p-1062 and GmPRP2p-852 constructs (Figure 4). The 5'-deletions of the GmPRP2p-1062 from
-1062 to -852 slightly increased GUS activity. A further deletion to -471 obviously decreased GUS activity, and a deletion to -369 was slightly better than -471 . However, the GUS expression level in these plants was much lower than in the transgenic plants with GmPRP2p-1062 and GmPRP2p-852 constructs. We speculated that the promoter fragment from -471 to -369 may contain the suppressor which induced the expression level increased in GmPRP2p-369 compared with GmPRP2p-471. The GUS activity in roots was obviously higher than in leaves, regardless of the promoter fragment except GmPRP2-471. The results of GUS staining and fluorometric GUS assays were uniform.

GUS expression was observed in the roots of all promoter fragment constructs, except the GmPRP2p-471 construct. GUS staining appeared in the petiole during the reproductive growth stage, and emerged in the split margins besides the abscission in siliques, but the expression levels were quite weak. GUS staining was not detected in flowers and seeds. Furthermore, GUS staining was not visible in any organs of plants containing the GmPRP2p-471 construct (Figure 5).

\section{MeJA and IAA increased and GA, ABA and SA decreased the GUS activity of the GmPRP2p-1062 and 5'-deletion fragments}

We tested the GUS activity in the roots of 20-day-old transgenic seedlings treated with $1 \mathrm{mM} \mathrm{SA}, 100 \mu \mathrm{M}$ MeJA, $100 \mu \mathrm{M}$ IAA, $100 \mu \mathrm{M}$ GA, and $100 \mu \mathrm{M}$ ABA for $24 \mathrm{~h}$ to assess the response of the GmPRP2p-1062 and 5'-deletion fragments to various hormones. Seedlings treated with $\mathrm{H}_{2} \mathrm{O}$ and wild type seedlings treated with the above stressors were used as controls. MeJA enhanced the GUS activity in transgenic seedlings containing the GmPRP2p-1062 construct compared to $\mathrm{H}_{2} \mathrm{O}$ control samples (Figure 6). The GUS activity was increased by 2.22-fold (P1062-9), 2.86-fold (P1062-14) 


$\begin{array}{rllllll}\text {A }^{-1062} & \text { ATTTTCCGGA } & \text { CAAACTCTGG } & \text { ATTAATCAGA } & \text { ATAGGGTCTC } & \text { TTTTTTCTGA } & \text { TGAATGGAAG } \\ -1002 & \text { GGTTAAAGAA } & \text { AAAAAAAATA } & \text { ACTTTCGTTT } & \text { ACGGGCGGTC } & \text { ATGCTTGTGA } & \text { TTTTGGAATT } \\ -942 & \text { GTTTCAAACA } & \text { AAATGGGTGC } & \text { GTGGAGTTTT } & \text { CCAAAATTG } & \text { TTGAAAAGAA } & \text { TTAAATTTGA } \\ -882 & \text { TCAAGTACTA } & \text { TGAGTATTCA } & \text { AGGCCAAATC } & \text { ATGGAAATTG } & \underline{\text { CAAATGCAAT }} & \text { TCAACAGGAA } \\ -822 & \text { AGCCTTGTT } & \text { GTGTTAATTT } & \text { CTAATCTAAC } & \text { ATAATGTTTC } & \text { TAATTTCAAT } & \text { TTAGCCAACT } \\ -762 & \text { CAATTTTGA } & \text { GCCAAATATC } & \text { ATATATGTT } & \text { TCAGTTAGAG } & \text { TAGTTTGCAG } & \text { ATCCGCATAC } \\ -702 & \text { GGGCCTTAAT } & \text { TAGTTTATAC } & \text { TATTATTTAG } & \text { TAGCATTCCT } & \text { TCATTAGGAT } & \text { TAATGGTTTA } \\ -642 & \text { TTTCTTGAAA } & \text { GAAAGAAAAA } & \text { AAAAGGTACT } & \text { AAACTATTAA } & \text { CTAATAATT } & \text { ACTTATACTA } \\ -582 & \text { CCATTATGTC } & \text { CATAAACTTG } & \text { ATCAGTAAGT } & \text { GTATAATAAG } & \text { TGATTTGAGC } & \text { CTAGCCAAAC } \\ -522 & \text { ATAGCAAATC } & \text { TCATACAACT } & \text { AAAGTATATA } & \text { TGCAGAAAGC } & \text { ATTTCTTGGC } & \text { TCTAATATGG } \\ -462 & \text { TATATATCTA } & \text { AATCAATTCT } & \text { CCAGTGTTAA } & \text { GACTCTTTTT } & \text { CTTTGTTAGT } & \text { TAGCAATTAA } \\ -402 & \text { TCATGAGTCA } & \underline{\text { AAACCAGAAA }} & \text { CTAGCTACTA } & \text { CACTCCCATG } & \text { CCATAATGCG } & \text { TAAAACAATT } \\ -342 & \text { CAATTATTTG } & \text { GTATGGCAAT } & \text { TGAAATTATT } & \text { TGTATTAACA } & \text { CCTTTCCAAA } & \text { GGAGACAAAG } \\ -282 & \text { ACGTCGGTGC } & \text { ATTGAGAAAT } & \text { GTGAAAAAAA } & \text { AATATTATCA } & \text { CTTGTGTGGA } & \text { CTTGTCAATG } \\ -222 & \text { TTCCCGTTAA } & \text { ATTTCCAACT } & \text { TTGCAACTAC } & \text { AAGAAGACAG } & \text { CATTCACCTA } & \text { CACAGCAATT } \\ -162 & \text { GAAAATCCAC } & \text { ACTGAAGATT } & \text { GACCTTTGTA } & \text { CAACGGTGCT } & \text { AGAAACCGCG } & \text { TCACTAGTAA } \\ -102 & \text { TAACTATTGG } & \text { ATTGAGACAT } & \text { GCACTTAACA } & \text { GTAAGGCCCC } & \text { CAACTAATAT } & \text { AAAAACCAGT } \\ -42 & \text { TATTGGGTGT } & \text { GTTACTCATC } & \text { AGCAACTACA } & \text { ACGTGAGAAA } & \text { CCATGGCTTC } & \text { CTTAAGCTCC } \\ 19 & \text { TTAGTGCTGC } & \text { TCCTTGCAGC } & \text { TCTAATTCTA } & \text { TCCCCTCAAG } & \text { TTCTTGCAAA } & \text { CTATGAGAAT } \\ 79 & \text { CCCCCAGTGT } & \text { ACAAGCCTCC } & \text { CACTGAGAAA } & \text { CCACCAGTTT } & \text { ATAAGCCCCC } & \text { AGTTGAGAAG } \\ 139 & \text { CCTCCTGTTT } & \text { ACAAACCTCC } & \text { AGTTGAAAAC } & \text { CCCCCA } & & \end{array}$

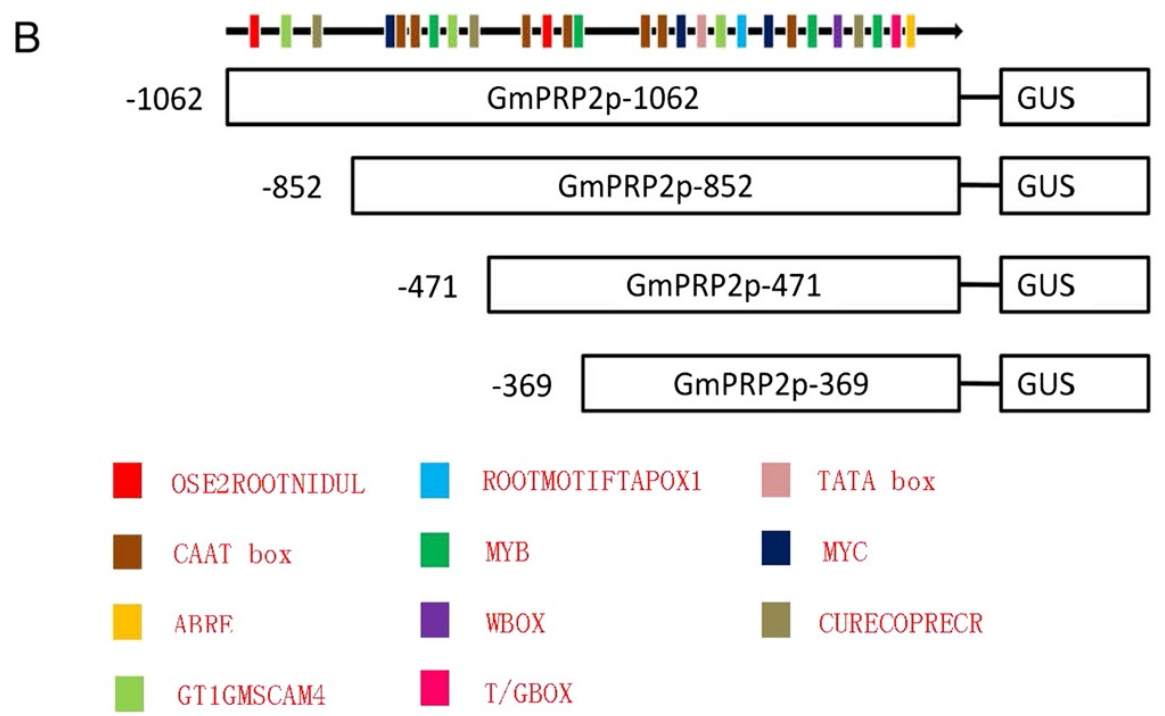

Figure 2 Sequence of the GmPRP2p-1062 denoting the cis-elements predicted by the PLACE and PlantCARE databases and schematic diagrams of truncated GmPRP2p-1062 constructs. A A 1,236 bp 5'-flanking region fragment of the PRP2 gene, containing 1062 bp promoter sequence. The translated start site is defined as +1. The TATA box, partial CAAT box, Wbox, ABRE, MYB, MYC, root-specific elements are underlined with different colors. B Schematic diagrams of truncated GmPRP2p-1062 constructs. The numbers on the left indicate 5'-deletion fragments of the promoter. Some cis-elements are also marked with the colored columns.

and 2.02-fold (P1062-16) in the three transgenic lines. Similar results were observed in seedlings transformed with the GmPRP2p-852, GmPRP2p-471 and GmPRP2p369 constructs. The GUS activity was increased one to three times in transgenic lines. IAA increased the GUS activity in most transgenic seedlings with different constructs by one to two times (Figure 6).
SA and GA treatments decreased the GUS activity approximately $40-70 \%$ in transgenic seedlings with the GmPRP2p-1062 construct and approximately $70-80 \%$ in transgenic seedlings with the GmPRP2p-852 construct. The GUS activity was decreased $70-90 \%$ in transgenic seedlings with the GmPRP2p-471 and GmPRP2p-369 constructs. ABA treatment slightly decreased the GUS 


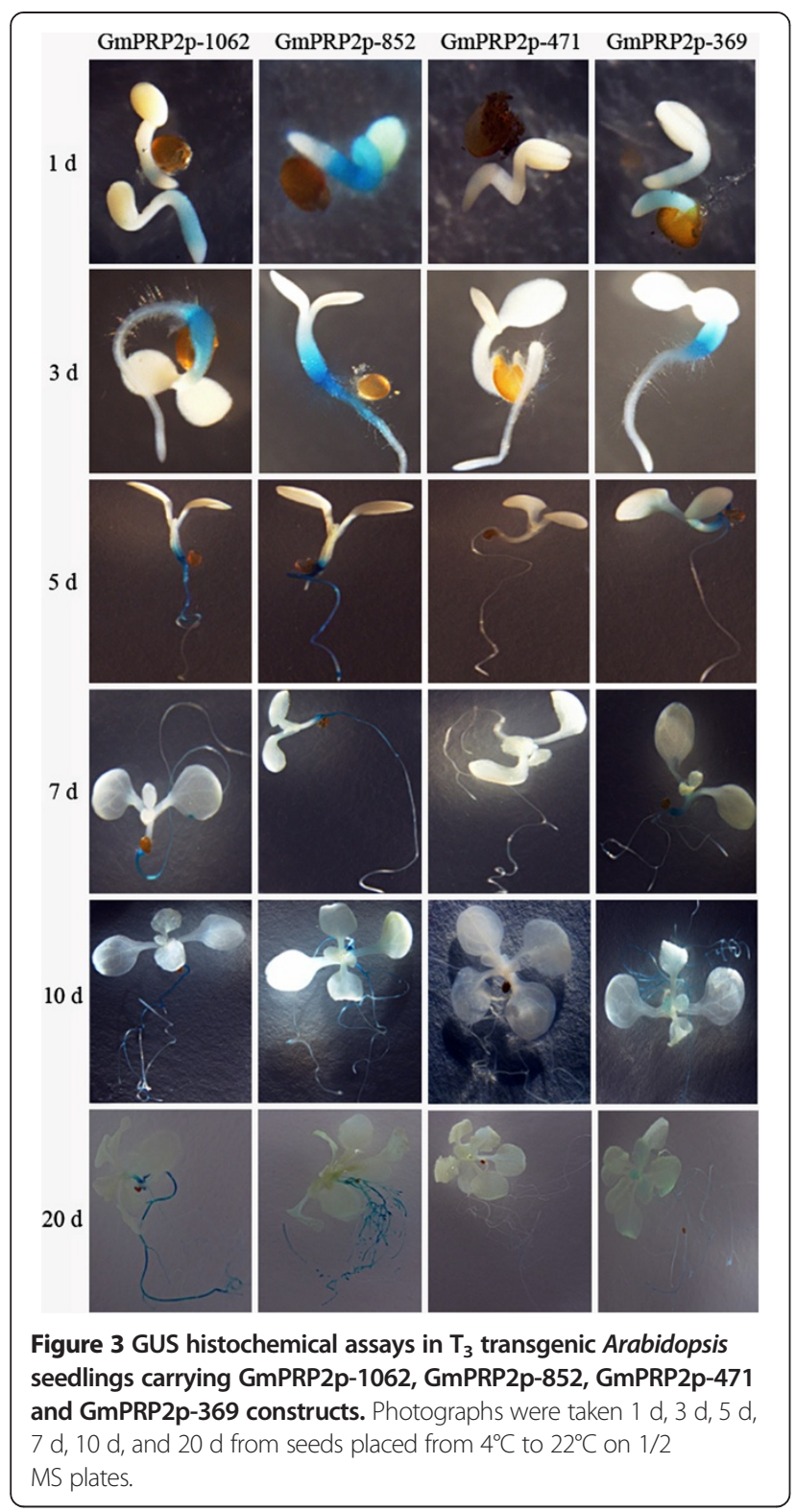

activity approximately 30-60\% in most transgenic seedlings compared to SA and GA treatments (Figure 6).

\section{$\mathrm{NaCl}$ and PEG increased the activity of the GmPRP2p-1062} and the $5^{\prime}$-deletion fragments

We tested GUS activity in the roots of 20-day-old transgenic seedlings treated with $200 \mathrm{mM} \mathrm{NaCl}$ and $20 \%$ PEG6000 for 24 h to identify the response of GmPRP2p1062 and 5'-deletion fragments to environmental stresses. The seedlings treated with $\mathrm{H}_{2} \mathrm{O}$ and wild type seedlings treated with the above stressor were used as controls. $\mathrm{NaCl}$ and PEG treatment enhanced GUS activity. $\mathrm{NaCl}$ treatment increased GUS activity by 3.19-fold (P1062-9), 1.05-fold (P1062-14) and 1.05-fold (P1062-16) in the three GmPRP2p-1062 transgenic lines. The GUS activity was increased one to two times in most of the transgenic lines with the other constructs (Figure 6). PEG treatment increased the GUS activity in all transgenic lines carrying different constructs, and greatly increased the GUS activity by 2.29-fold (P471-4), 3.24-fold (P471-6) and 4.08-fold (P471-7) in the GmPRP2p-471 transgenic lines (Figure 6). However, the GUS levels were much lower in the GmPRP2p-471 transgenic lines than in the GmPRP2p-1062 and GmPRP2p-852 transgenic lines (Figure 6).

\section{The expression patterns of GmPRP2p-1062 and the}

\section{5 '-deletion fragments in soybean hairy roots}

Numerous branched roots developed from each wound site on the cotyledon after Agrobacterium rhizogenes $\mathrm{K} 599$ infection and co-cultivation. The entire cotyledon with hairy roots was used for GUS staining. The $35 \mathrm{~S}$ promoter drove strong GUS staining (Figure 7). GmPRP2p-1062, GmPRP2p-852 and GmPRP2p-369 also drove GUS staining in soybean hairy roots, but GUS staining was not detected in transgenic GmPRP2p-471 hairy roots. The transformant PC13P1 vector was used as a negative control.

We used GUS staining to select positive roots because the hairy roots from cotyledon were not all positive. For each promoter construct, twenty soybean cotyledons as explants were used to transform. Thirty to fifty hairy roots from each transgenic promoter cotyledons were examined for GUS staining. The hairy roots of transgenic GmPRP2p471 constructs were also detected using PCR. Ten GUSpositive hairy roots of each transgenic construct were used to measure GUS activity. The GUS activity results were used for statistical analysis. The $35 \mathrm{~S}$ promoter drove the highest GUS expression level compared to the maximum expression level of each transgenic construct (Figure 8). The GUS expression levels in all transgenic GmPRP2p1062 and 5'-deletion fragments were lower than that in the $50^{\text {th }}$ percentile of the $35 \mathrm{~S}$ promoter. The GUS expression levels for GmPRP2p-1062 and GmPRP2p-852 were higher than those of the lowest GUS expression level of the $35 \mathrm{~S}$ promoter. The GUS expression levels of most hairy roots for GmPRP2p-369 were less than the minimum of the 35S promoter, GmPRP2p-1062 and GmPRP2p-852. The expression activity of GmPRP2p-471 was extremely weak, and GUS staining was not detectable by eyes. The maximum GUS expression of GmPRP2p-1062 was higher than that of GmPRP2p-852. But the GUS expression in the $50^{\text {th }}$ percentile of GmPRP2p-1062 lines was lower than those of GmPRP2p-852 (Figure 8).

\section{Discussion}

PRPs are a structural cell wall protein in plants [37]. Previous studies of PRPs predominantly focused on gene expression and showed that PRPs are regulated 


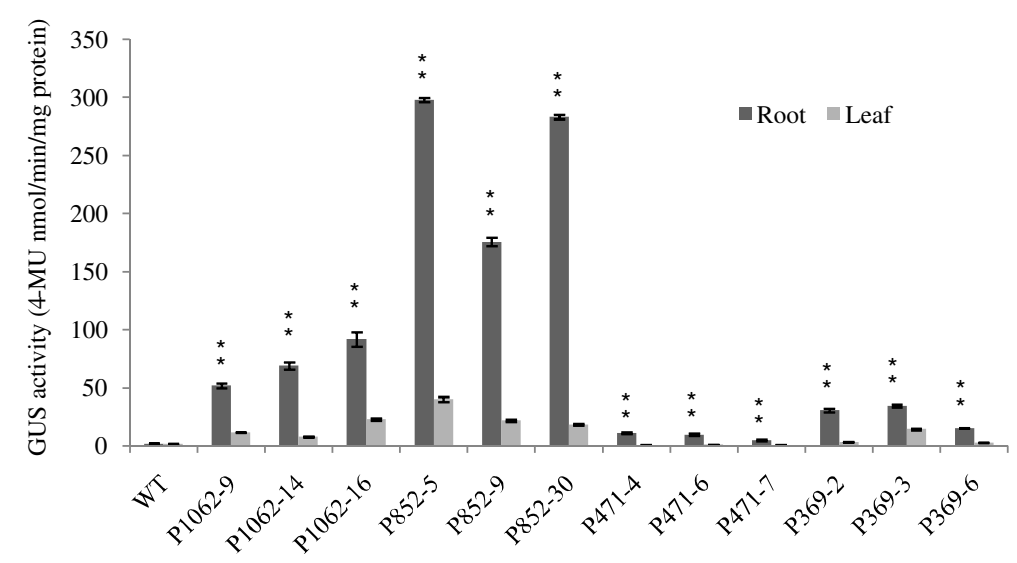

Figure 4 GUS activity assays in $T_{3}$ transgenic Arabidopsis roots and leaves carrying GmPRP2p-1062, GmPRP2p-852, GmPRP2p-471 and GmPRP2p-369 constructs. GUS activity assays in $T_{3}$ transgenic Arabidopsis roots and leaves carrying different deletion fragments of the GmPRP2p-1062. Each promoter fragment had three transgenic lines. P1062-9, P1062-14, and P1062-16 are the three transgenic lines carrying the GmPRP2p-1062 construct; P852-5, P852-9, and P852-30 are the three transgenic lines carrying the GmPRP2p-852 construct; P471-4, P471-6, and P471-7 are the three transgenic lines carrying the GmPRP2p-471 construct; P369-2, P369-3, and P369-6 are the three transgenic lines carrying the GMPRP2p-369 construct. Data are the means of three replicates with SE shown by vertical bars. ${ }^{* *}$ differ significantly by one-sided paired $t$ test at $P<0.01$.

spatiotemporally during the development of a particular tissue or cell type [29-31]. For example, Arabidopsis $P R P 1$ and $P R P 3$ were exclusively expressed in roots, and $P R P 2$ and $P R P 4$ transcripts were abundant in aerial organs of the plant $[40,41]$. The rice OsPRP3 expression was mainly present in flowers and accumulated during the late stage of flower development [42]. OsPRP1 is expressed preferentially in spikelets and buds, but expression is lower in roots and leaves [43]. The cotton GhHyPRP3 mRNA was abundant in petals and 10-DPA ovules but lower in roots and cotyledons and absent in leaves and anthers [44]. Therefore, PRPs exhibit an organ-preferential expression pattern to meet the functional and physical requirements of different cell types at different developmental stages.

PRP promoters play an important role in the organpreferential expression pattern of PRPs. Xu et al. reported that GhPRP5 is a fiber-specific gene, and its promoter directs GUS expression only in the trichomes of both transgenic Arabidopsis and tobacco plants [32]. The transcript of the alfalfa MsPRP2 gene is expressed in a root-specific manner, and GFP driven by the $M S P R P 2$ promoter is also expressed in the root [45]. These studies promote an understanding of the mechanism of organ-preferential expression and provide more promoter options for genetic engineering.

The expression of GmPRP1 and GmPRP2 in soybeans is also root-specific [29-31], but little is known about their promoters and regulatory mechanisms. Here, we cloned the GmPRP2 promoter (GmPRP2p-1062), which contained many important cis-elements, such as the TATAbox, CAATbox, MYB, MYC, ABRE and root-related elements (Figure 2).
GUS staining showed a root-preferential expression in the vegetative stage in the model plant Arabidopsis (Figure 3). Therefore, GmPRP2p-1062 can harbor some cis-regulatory elements and drive a root-preferential expression. Three 5'-deletion fragments (GmPRP2p-852, GmPRP2p-471, GmPRP2p-369) also exhibited rootpreferential expression, but the expression levels were significantly different. In our study, we detected that expression level in GmPRP2p-471 was very low, then when a further deletion the expression level in GmPRP2p-369 was increased, so we speculated that the suppressor may exist in the promoter fragment from -471 to -369 . The elements in these deletion regions, which might be responsible for the root specificity and expression, require further research. The study of GmPRP2p-1062 and 5'deletion fragments in soybean hairy roots showed that the expression patterns were similar to the transgenic Arabidopsis (Figure 7), and GUS activity was much higher with the GmPRP2p-1062 and GmPRP2p-852 constructs than the other two constructs. The homogeneity in soybean and Arabidopsis inferred that the PRP2 promoter has a similar expression pattern in dicotyledonous plants. The expression level was highest in transgenic Arabidopsis with the GmPRP2p-852 construct, and the range of GUS activity varied little between the ten transgenic hairy roots with the GmPRP2p-852 construct compared with the other constructs (Figure 8). Therefore, the GmPRP2p-852 may be suitable for application.

Histochemical staining of GUS activity during reproductive growth was also observed in the petiole of green leaves and the split margins in siliques in all promoter constructs except the GmPRP2p-471, but the expression level was much lower than in roots. GUS staining was not 


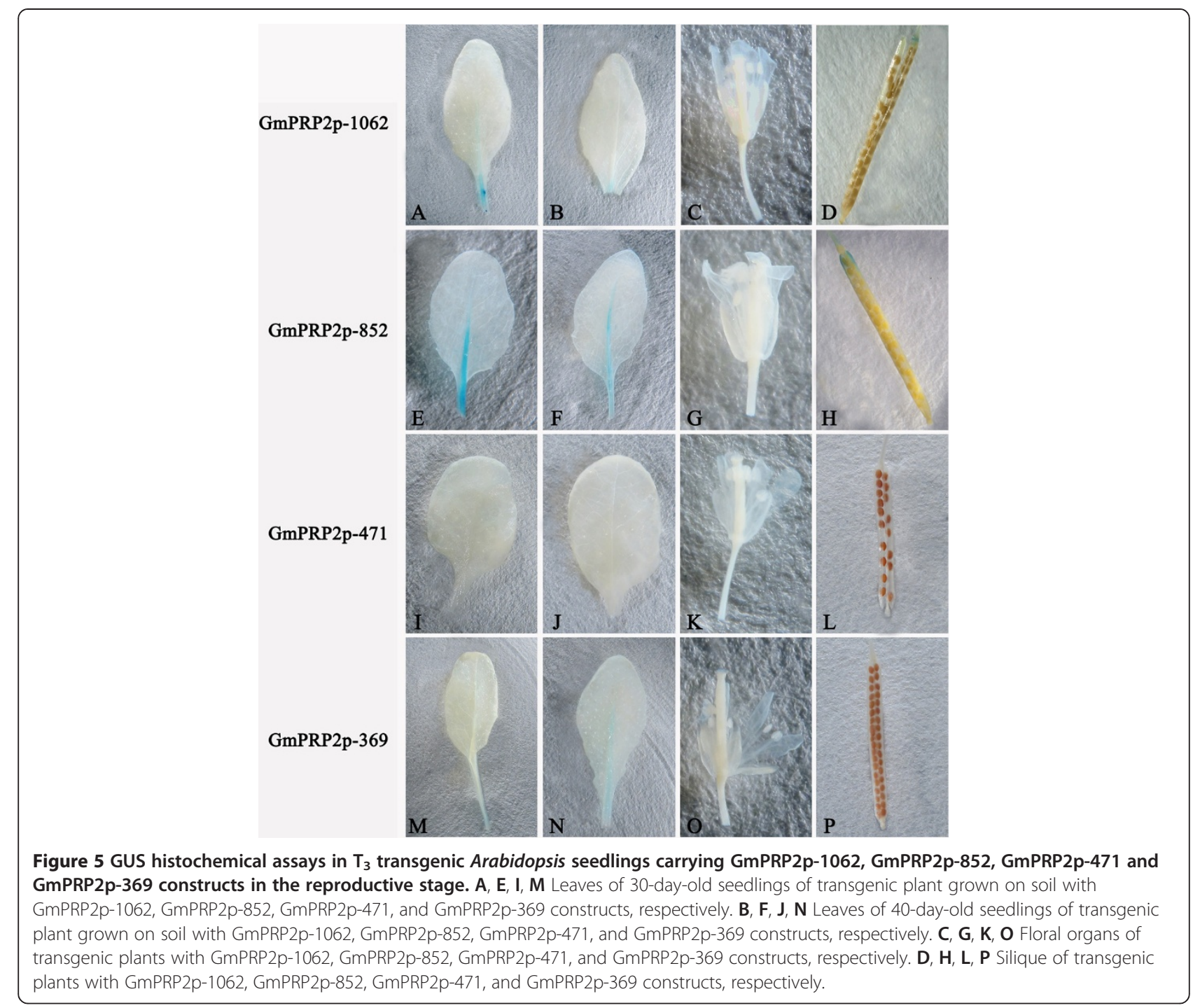

observed in flowers and seeds (Figure 5). GUS staining was also detected in the main veins in transgenic lines with the GmPRP2P-852 construct, which exhibited high expression levels. This result indicated that GmPRP2 may be expressed in only a few tissues during the reproductive stage and suggested that the promoter may be suitable for genetic engineering with little concern about food safety.

Biotic and abiotic stresses also influenced the expression of PRPs. Some evidence indicated that many internal and external factors, such as wounding, fungal infection, circadian rhythm, salt stress, drought stress, and plant regulators, up or down regulates the expression of PRPs [36,38]. For example, Alfalfa MsPRP2 is salt-inducible [46]. Low temperature induced transcripts of Brassica napus BnPRP. The bean PvPRP1 mRNA initially decreases then increases in wounded hypocotyls and decreases in the elicitor [38].
Cotton GhHyPRP3 transcription in roots was up-regulated by salt stress, cold stress, and osmotic stress and downregulated by $\mathrm{GA}_{3}$ [44]. $P R P$ gene expression is complicated with positive or negative regulation by stresses. The diversity of the promoter may regulate gene expression in many biological processes. Our results showed that the activity of the GmPRP2p-1062 promoter was differentially regulated in response to various abiotic factors. $\mathrm{NaCl}, \mathrm{PEG}, \mathrm{JM}$ and IAA up-regulated the activity, and $\mathrm{ABA}, \mathrm{GA}$, and SA down-regulated the activity (Figure 6). The deletion fragments contained stress elements. The -1062 to -853 fragment contained a copperand salt-responsive element, and -852 to -472 contained light- and salt-responsive elements. The three 5'-deletion fragments showed a similar response to the stress factors treated with the GmPRP2p-1062. The region from -369 to +1 is rich in various biotic and abiotic stress-related cis- 


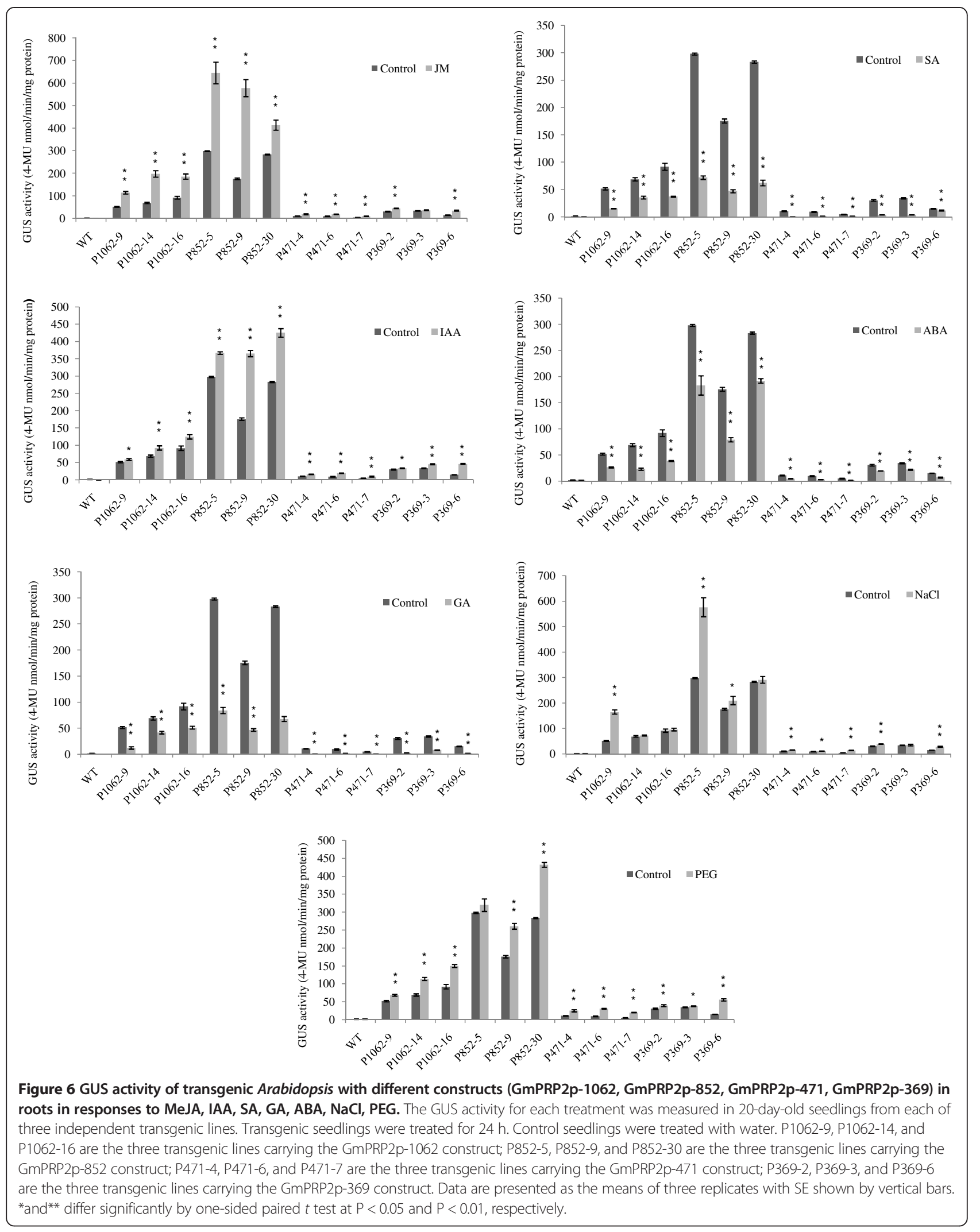




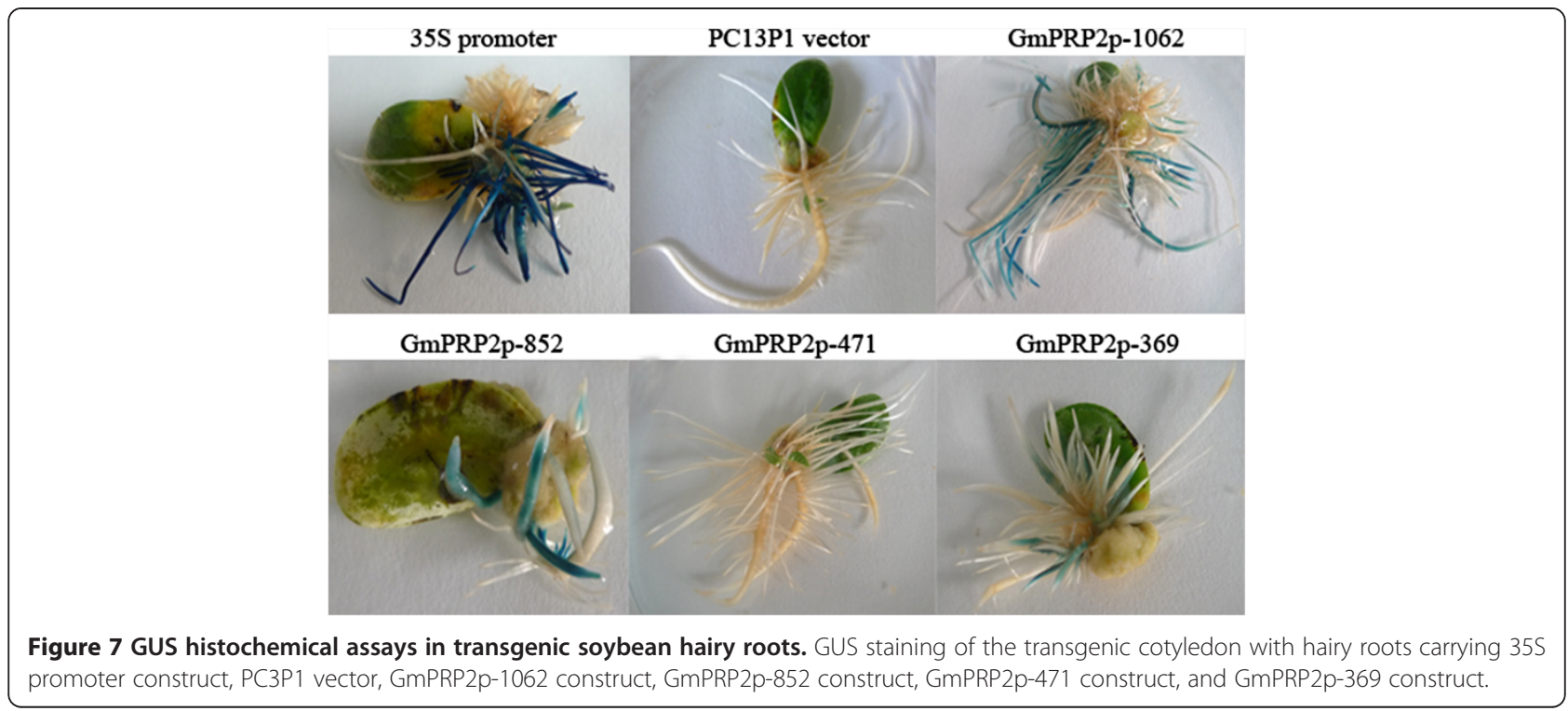

elements, including four CAATBOX, two MYB and three MYC cis-elements, two ARR1 cis-elements, one ABRE ciselement, one WBOX and one T/GBOX (Additional file 1), and this region is a crucial part of the promoter. MYB and MYC recognition sites may contribute to the activation of drought- and ABA-regulated gene expression. ABRE was identified as an ABA-responsive element. WBOX was involved in the activation of the ERF3 gene by wounding, and the T/GBOXATPIN2 element at -13 was involved in jasmonate signaling (Additional file 1). The above studies demonstrated that the PRP2 promoter may regulate gene expression on the transcriptional level.

The fine regulation of transgene expression levels is not easy to obtain due to the lack of available promoters. This work provided important insights into the promoter regions that control spatial- and stressspecific expression. This promoter could be widely used as a tool in genetic engineering. Soybeans are an important source of nutrition worldwide, but soybeans are generally considered salt- and drought-sensitive. Soybean roots also suffer from severe diseases that lead

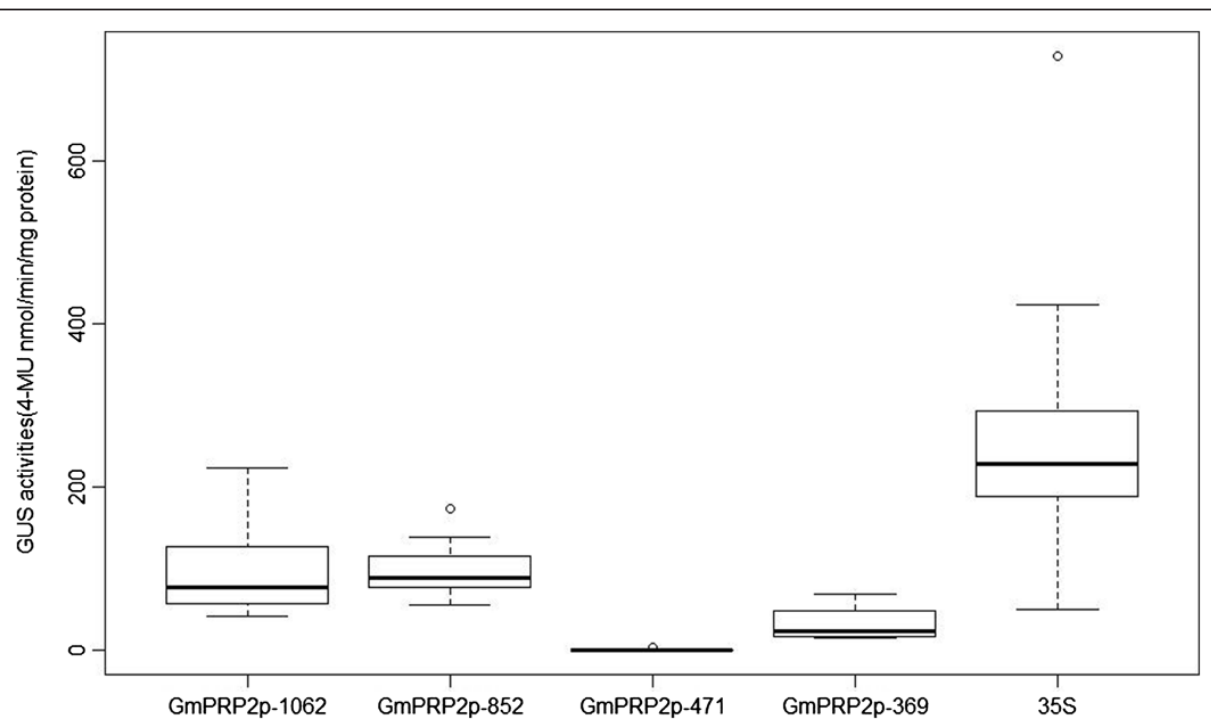

Figure 8 GUS activity of transgenic soybean hairy roots with different constructs (GmPRP2p-1062, GmPRP2p-852, GmPRP2p-471, GmPRP2p-369, 35S). Box plot analysis of GUS activities obtained in transgenic soybean hairy roots with different constructs (GmPRP2-1062, GmPRP2-852, GmPRP2-471, GmPRP2-369, 35S). GUS activity is given in nmol 4-MU $\mathrm{min}^{-1} \mathrm{mg}^{-1}$ total protein. The lower boundary of each box denotes the $25^{\text {th }}$ percentile for each promoter, the solid line within each box denotes the $50^{\text {th }}$ percentile, the upper boundary of each box denotes the $75^{\text {th }}$ percentile. Two ends of the vertical line denote the maximum and minimum. Outlying data are indicated by empty black circles. 
to large annual losses. This promoter is promising for the engineering of resistance traits in soybeans.

\section{Conclusions}

GmPRP2p-1062 is a root-preferential promoter, and the core fragment for root expression might reside between -369 and +1 . The expression activity for this promoter was lower with shorter promoter sequences from -471 to $-369 \mathrm{bp}$, and environmental stresses altered expression activity. GmPRP2p-852 may be used in soybean genetic engineering to improve root tolerance and resistance in the future.

\section{Methods}

\section{Plant material and growth condition}

Seeds of the soybean cultivar Williams 82 were grown in pots filled with vermiculite under $12 \mathrm{~h}$ light $/ 12 \mathrm{~h}$ dark cycles at $28^{\circ} \mathrm{C}$. The root tissues were cut for genomic DNA extraction after the first true leaf opening. Seeds of Arabidopsis thaliana (Columbia) were surface-sterilized with $10 \% \mathrm{NaClO}$ for $15 \mathrm{~min}$ and washed four times with sterile water. The sterilized Arabidopsis seeds were placed on 1/2 MS medium, and the plates were transferred to a plant growth incubator for seed germination under $16 \mathrm{~h}$ light $/ 8 \mathrm{~h}$ dark at $22^{\circ} \mathrm{C}$ after stratification at $4^{\circ} \mathrm{C}$ for 3 days.

\section{Analysis of GmPRP2 tissue expression pattern by qRT-PCR} The total RNA was isolated from soybean different tissues of root, stem, leaf, flower, seed, and hypocotyl using Trizol agent (Trans). cDNAs were synthesized from 800 ng total RNA using the M-MLV reverse transcriptase and oligodT primer according to the manufacturer's instructions (Promega). qRT-PCR reactions (20 $\mu$ l volume containing $2 \mu \mathrm{l} \mathrm{cDNA}$ as the template) were performed using the StepOne real-time PCR system (Applied Biosystems 7500) in standard mode with the KAPA SYBR FAST Universal qRT- PCR kit (KAPA Biosystems). Each tissue has three samples, and each sample of one tissue was performed in triplicate. The soybean Actin gene was used as the internal control. The primers for GmPRP2 were $5^{\prime}$ - GCTCCTTAGTGCTGCTCCTT-3' and 5' -TC AGTGGGAGGCTTGTACA-3'. The primers for Actin were 5'-CGTTTCATGAATTCCAGTAGC-3' and 5' - GA GCTATGAATTGCCTGATGG-3'.

\section{Cloning of the GmPRP2 promoter}

Genomic DNA was isolated from the roots of soybean using the CTAB method. Two primers were designed according to the sequence of GmPRP2 and its upstream sequence from the soybean genome database: the upstream primer F1 (5'-ATTTTCCGGACAAACTCTGG-3') and downstream primer R1 (5'-TGGGGGGTTTTCAACTGGAG-3'). PCR cycling parameters were as follows: $94^{\circ} \mathrm{C} 5$ min; $94^{\circ} \mathrm{C} 30 \mathrm{~s}, 55^{\circ} \mathrm{C} 30 \mathrm{~s}, 72^{\circ} \mathrm{C} 2 \mathrm{~min}, 35$ cycles; $72^{\circ} \mathrm{C}$ for
10 min. The first PCR product contained a partial coding sequence, so another downstream primer R2 (5'-GGTTTCTCACGTTGTAGTTG-3') that contained no coding sequence was designed. The second round of PCR was amplified with the F1 and R2 primers using the first PCR product as the template. The PCR cycling parameters were as follows: $94^{\circ} \mathrm{C} 5 \mathrm{~min} ; 94^{\circ} \mathrm{C} 30 \mathrm{~s}, 52^{\circ}$ C $30 \mathrm{~s}, 72^{\circ} \mathrm{C} 2 \mathrm{~min}, 35$ cycles; $72^{\circ} \mathrm{C}$ for $10 \mathrm{~min}$. The PCR products were cloned into pEASY-T1 vector and sequenced.

PCR amplification of 5'-deletion fragments of the GmPRP2 promoter

We designed three forward primers to obtain 5'-deletion fragments of the GmPRP2 promoter: F-852 (5'-ATGGAAATTGCAAATG-3'), F-471 (5' -CTAATATGGTATATATC-3'), and F-369 (5'-TCCCATGCCATAATGCG-3'). The same reverse primer, R2, amplified the promoter deletion at -852 (F-852/R2), -471 (F-471/R2), and -369 (F-369/R2), respectively. The PCR cycling parameters were as follows: $94^{\circ} \mathrm{C} 5 \mathrm{~min} ; 94^{\circ} \mathrm{C} 30 \mathrm{~s}, 52^{\circ} \mathrm{C} 30 \mathrm{~s}$, $72^{\circ} \mathrm{C} 1 \mathrm{~min}, 35$ cycles; $72^{\circ} \mathrm{C}$ for $10 \mathrm{~min}$. The promoter fragments were cloned into pEASY-T1 vector and confirmed by sequencing. The GmPRP2 promoter was named the GmPRP2p-1062, and the three 5'-deletion fragments were named GmPRP2p-852, GmPRP2p-471, and GmPRP2p-369.

\section{Bioinformatics analysis of the promoter sequence}

Regulatory elements in promoter regions were analyzed using the online program PLACE (a database of plant cis-acting regulatory DNA elements) [47] and PlantCARE (a database of plant cis-acting regulatory elements, enhancers and repressors) [48]. These two programs are available at http://www.dna.affrc.go.jp/PLACE/ and http://bioformatics.psb.ugent.be/webtools/plantcare/html/, respectively.

\section{Construction of the promoter-GUS reporter plasmid and Arabidopsis transformation}

$\mathrm{SacI}$ and $\mathrm{XbaI}$ digested the pEASY-T1 vector (TransGene Bioteck) and pC13P1 vector (Additional file 2). A $1062 \mathrm{bp}$ GmPRP2 promoter was ligated into the vector $\mathrm{pC} 13 \mathrm{P} 1$ with $S a c I$ and $X b a I$ digestion to construct the GmPRP2p:: GUS vector. The 5'-deletion promoter fragments were fused to the GUS reporter gene of the pC13P1 vector using the same method described above.

The constructs and a selected vector pC(Delt)GUS (Additional file 3) plasmid were introduced into Agrobacterium tumefaciens GV3101 using electroporation [21]. The Agrobacterium liquids (1:1 v/v) mixed with the constructs and pC(Delt)GUS vector were transformed into Arabidopsis (Col-0) using the flower dipping method [49]. Transformants were selected by planting the seeds 
on $1 / 2$ MS plates containing $50 \mathrm{mg} / \mathrm{L}$ hygromycin $\mathrm{B}$. The positive transformants were confirmed using PCR. The PCR primers were F1/R2 for transgenic GmPRP2p-1062 plants, F-851/R2 for transgenic GmPRP2p-851 plants, F471/R2 for transgenic GmPRP2p-471 plants, and F-369/ R2 for transgenic GmPRP2p-369 plants. The homozygous transgenic plants were confirmed using genetic analysis of the segregation ratio of later generations.

\section{Treatment with abiotic stress}

To characterize the induced activities of the GmPRP2p1062 and 5'-deletion fragments in response to different defense signal molecules, we treated transgenic Arabidopsis plants with $\mathrm{NaCl}$, PEG6000, abscisic acid (ABA), salicylic acid (SA), methyl jasmanate (MeJA), indole-3acetic acid (IAA), and gibberellins acid (GA). Twentyday-old transgenic plants were used for the following treatments. The roots were immersed in $200 \mathrm{mM} \mathrm{NaCl}$, 20\% PEG6000, $100 \mu \mathrm{MABA}, 1 \mathrm{mM} \mathrm{SA}, 100 \mu \mathrm{M} J \mathrm{M}$, and $100 \mu \mathrm{M}$ GA water solutions for $24 \mathrm{~h}$, frozen in liquid nitrogen and stored at $-80^{\circ} \mathrm{C}$ for protein extraction and GUS fluorometric assays. The control plants were incubated in water. The wild type Arabidopsis also served as a control.

\section{Soybean hairy root transformation}

The plasmids of GmPRP2p-1062 and 5'-deletion fragments vectors were introduced into the Agrobacterium rhizogenes strain $\mathrm{K} 599$ to induce expression in hairy roots [50]. Soybean cv. Zigongdongdou was screened for transformation. Seeds were surface sterilized for $16 \mathrm{~h}$ using chlorine gas, which was produced by mixing $3.5 \mathrm{~mL}$ of $12 \mathrm{~N} \mathrm{HCl}$ and $100 \mathrm{~mL}$ commercial bleach in a tightly sealed dessicator. Sterilized seeds were germinated in B5 medium, and entire cotyledons from 5-dayold seedlings as explant were harvested and wounded with a scalpel, which was previously dipped into an overnight culture of A. rhizogenes strain K599 carrying GmPRP2p-1062::GUS vector, GmPRP2p-852::GUS vector, GmPRP2p-471::GUS vector, GmPRP2p-369::GUS vector, 35S::GUS vector and PC13P1 vector. Subsequently, the entire cotyledons were immersed into $A$. rhizogenes culture and shaken $(50 \mathrm{rpm})$ at $25^{\circ} \mathrm{Cfor}$ $30 \mathrm{~min}$. Explants were dried on sterile filter paper and transferred to co-cultivation medium (CCM) containing $10 \%$ MS, $3.9 \mathrm{~g} / \mathrm{L}$ morpholino ethanesulfonic acid, $150 \mathrm{mg} / \mathrm{L}$ cysteine and $150 \mathrm{mg} / \mathrm{L}$ dithiothreitol. The CCM was covered with sterile filter paper and incubated under a $16 \mathrm{~h}$ light $/ 8 \mathrm{~h}$ dark cycle condition at $24^{\circ}$ C. Entire cotyledons were cultured 5 days later on $1 / 2$ MSB medium (1/2 Murashige and Skoog basal nutrient salts, B5 vitamins, $3 \%$ Suc and $3 \mathrm{~g} / \mathrm{L}$ phytagel, $\mathrm{pH}$ 5.7) [50]. Approximately 10-12 d after root emergence, $1 \mathrm{~cm}$-long root tips or the bottoms of each root were cut for GUS staining. We selected GUS-positive roots for measurement of GUS activity.

\section{GUS histochemical and fluorometric analyses}

Histochemical and fluorometric GUS assays were performed according to Jefferson [51]. The tissues were placed in GUS staining solution $(50 \mathrm{mM}$ sodium phosphate, pH7.0, $0.5 \mathrm{mM}$ potassium ferrocyanide, $0.5 \mathrm{mM}$ potassium ferricyanide, $0.5 \mathrm{mg} / \mathrm{ml}$ 5-bromo-4 chloro-3indolyl- $\beta$-D- glucuronide (X-Gluc), $0.1 \%$ Triton X-100 and $20 \%$ methanol) and incubated at $37^{\circ} \mathrm{C}$ overnight. After staining, tissue samples were bleached with $50 \%$ ethanol, $70 \%$ ethanol and $90 \%$ ethanol for $1 \mathrm{~h}$ each and immersed in $70 \%$ ethanol overnight. GUS staining was observed under a Nikon SMZ1500 microscope and photographed with a Nikon DS-Fil.

Tissues were homogenized to a fine power with liquid nitrogen and vortexed with $1 \mathrm{ml}$ GUS extraction buffer (50 mM sodium phosphate, $\mathrm{pH}$ 7.0, $10 \mathrm{mM}$ EDTA, $\mathrm{pH}$ 8.0, $10 \mathrm{mM} \beta$-mercaptoethanol, 0.1\% Triton X-100) for the fluorometric GUS assays. The samples were centrifuged for $10 \mathrm{~min}$ at $15,000 \mathrm{rpm}, 4^{\circ} \mathrm{C}$, and the supernatant was collected. Each sample was incubated in assay buffer (4-methylumbelliferyl- $\beta$ - $D$-glucuronide (4-MUG)) at $37^{\circ} \mathrm{C}$ for $60 \mathrm{~min}$. The reaction was stopped by the addition of $0.2 \mathrm{M} \mathrm{Na}_{2} \mathrm{CO}_{3}$. One blank was prepared per sample with a 0 -min incubation. Fluorescence was measured on an F-280 Luminescence Spectrometer with excitation at $365 \mathrm{~nm}$ and emission at $455 \mathrm{~nm}$. Protein concentration in supernatant was assessed using the Bradford method with bovine serum albumin (BSA) as a standard [52]. GUS activity was calculated as nanomoles of 4-Methylumbelliferone (4-MU) per minute per milligram of protein.

\section{Additional files}

\section{Additional file 1: Table S1. Putative cis-acting elements in the} GmPRP2p-1062 by PLACE and PlantCARE.

Additional file 2: Figure S1. The $\mathrm{PC} 13 \mathrm{P} 1$ vector.

Additional file 3: Figure S2. The pC(Delt)GUS vector.

\section{Abbreviations}

PRP: Proline-rich protein; GUS: $\beta$-Glucuronidase gene; MS: Murashige and Skoog medium; IAA: Indole-3-acetic acid; MeJA: Methyl jasmanate; ABA: Abscisic acid; SA: Salicylic acid; GA: Gibberellins acid; MU: 4-Methylumbelliferone; BSA: Bovine serum albumin; MUG: 4-methylumbelliferyl- $\beta$-D-glucuronide; X-Gluc: 5-bromo-4 chloro-3-indolyl- $\beta$-D- glucuronide.

\section{Competing interests}

The authors declare that they have no competing interests.

\section{Author contributions}

LC performed all of the experiments, data analysis, and manuscript drafting and revising; BJ provided technical support and revised the manuscript; CW took photographs; SS assisted in plant providing material; WH and TH designed the study, revised the manuscript and provided financial support. All authors read and approved the final manuscript. 


\section{Acknowledgments}

We would like to express our thanks to Professor Pedro S.C.F. Rocha for his gift of the $\mathrm{pC} 13 \mathrm{P} 1$ vector and $\mathrm{pC} 13$ (Delt)GUS vector. This project was supported by the China Agriculture Research System (CARS-04), the Major Science and Technology Projects of China (2013ZX08010-004), and CAAS Innovation Project.

Received: 20 November 2013 Accepted: 9 September 2014

Published online: 16 September 2014

\section{References}

1. Li Y, Sun Y, Yang Q, Kang J, Zhang T, Gruber MY, Fang F: Cloning and function analysis of an alfalfa (Medicago sativa L.) zinc finger protein promoter MsZPP. Mol Biol Rep 2012, 39:8559-8569.

2. Fang RX, Nagy F, Sivasuramaniam S, Chua NH: Multiple cis-regulatory elements for maximal expression of the Cauliflower Mosaic Virus $35 \mathrm{~S}$ promoter in transgenic plants. Plant Cell 1989, 1:141-150.

3. Bhullar S, Chakravarthy S, Advani S, Datta S, Pental D, Burma PK: Strategies for development of functionally equivalent promoters with minimum sequence homology for transgene expression in plants: cis-elements in a novel DNA context versus domain swapping. Plant Physiol 2003, 132:988-998.

4. Charrier B, Scollan C, Ross S, Zubko E, Meyer P: Co-silencing of homologous transgenes in tobacco. Mol Breed 2000, 6:407-419.

5. Xu L, Ye R, Zheng Y, Wang Z, Zhou P, Lin Y, Li D: Isolation of the endospermspecific LPAAT gene promoter from coconut (Cocos nucifera $\mathrm{L}$.) and its functional analysis in transgenic rice plants. Plant Cell Rep 2010, 29:1061-1068.

6. Zhang WW, Gao QR, Yang MM, Liu H, Wang D: Assay and characterization of an osmolarity inducible promoter newly isolated from Bacillus subtilis. Mol Biol Rep 2012, 39:7347-7353.

7. Saad RB, Romdhan WB, Zouari N, Azaza J, Mieulet D, Verdeil JL, Guiderdoni E, Hassairi A: Promoter of the AISAP gene from the halophyte grass Aeluropus littoralis directs developmental-regulated, stress-inducible, and organ-specific gene expression in transgenic tobacco. Transgenic Res 2011, 20:1003-1018.

8. Nan L, Lin H, Guan Y, Chen F: Functional analysis of cis-acting sequences regulating root-specific expression in transgenic tobacco. Chin Sci Bull 2002, 47:1441-1445

9. Xu X, Guo S, Chen K, Song H, Liu J, Guo L, Qian Q, Wang H: A 796 bp PSPR10 genepromoter fragment increased root-specific expression of the GUS reporter gene under the abiotic stresses and signal molecules in tobacco. Biotechnol Lett 2010, 32:1533-1539.

10. Liu JJ, Ekramoddoullah AKM: Root-specific expression of a western white pine $P R 10$ gene is mediated by different promoter regions in transgenic tobacco. Plant Mol Biol 2003, 52:102-120.

11. Noh SA, Lee HS, Huh GH, Oh MJ, Paek KH, Shin JS, Bae JM: A sweet potato SRD1 promoter confers strong root-, taproot-, and tuber-specific expression in Arabidopsis, carrot, and potato. Transgenic Res 2012, 21:265-278

12. Chen L, Tu Z, Hussain J, Cong L, Yan Y, Jin L, Yang G, He G: Isolation and heterologous transformation analysis of a pollen-specific promoter from wheat (Triticum aestivum L.). Mol Biol Rep 2010, 37:737-744.

13. Rogers HJ, Bate N, Combe J, Sullivan J, Sweetman J, Swan C, Lonsdale DM, Twel D: Functional analysis of cis-regulatory elements within the promoter of the tobacco late pollen gene g10. Plant Mol Biol 2001 45:577-585

14. Swapna L, Khurana R, Vijaya Kumar S, Tyagi AK, Rao KV: Pollen-Specific Expression of Oryza sativa Indica Pollen Allergen Gene (OSIPA) Promoter in Rice and Arabidopsis Transgenic Systems. Mol Biotechnol 2011, 48:49-59.

15. Lang Z, Zhou P, Yu J, Ao G, Zhao Q: Functional characteriztion of the pollen-specific $S B g L R$ promoter from potato (Solanum tuberosum $L$.). Planta 2008, 227:387-396

16. Chung KJ, Hwang SK, Hahn BS, Kim KH, Kim JB, Kim YH, Yang JS, Ha SH: Authentic seed-specific activity of the Perilla oleosin 19 gene promoter in transgenic Arabidopsis. Plant Cell Rep 2008, 27:29-37.

17. Zavallo D, Bilbao ML, Esteban Hopp H, Heinz R: Isolation and functional characterization of two novel seed-specific promoters from sunflower (Helianthus annuus L.). Plant Cell Rep 2010, 29:239-248.

18. van Haaren MJJ, Houck CM: A functional map of the fruit-specific promoter of the tomato $2 A 11$ gene. Plant Mol Biol 1993, 21:625-640.
19. Deikman J, Xu RL, KneissI ML, Ciardi JA, Kim KN, Pelah D: Separation of cis elements responsive to ethylene, fruit development, and ripening in the 5 '-flanking region of the ripening-related E8 gene. Plant Mol Biol 1998, 37:1001-1011

20. Moon H, Callahan AM: Developmental regulation of peach ACC oxidase promoter-GUS fusions in transgenic tomato fruits. J Exp Bot 2004, 55:1519-1528

21. Lü S, Gu H, Yuan X, Wang X, Wu A, Qu L, Liu J: The GUS reporter-aided analysis of the promoter activities of a rice metallothionein gene reveals different regulatory regions responsible for tissue-specific and inducible expression in transgenic Arabidopsis. Transgenic Res 2007, 16:177-191.

22. Hartman GL, West ED, Herman TK: Crop that feed the World 2. Soybeanworldwide production, use, and constraints caused by pathogens and pests. Food Security 2011, 3:5-17.

23. Wrather JA, Koenning SR: Estimates of Disease effects on soybean yields in the United States 2003 to 2005. J Nematol 2006, 38:173-180.

24. Owen MDK: Current use of transgenic herbicide-resistant soybean and corn in the USA. Crop Prot 2000, 19:765-771.

25. Winicov I, Deutch CE: Characterization of a CDNA clone from salt-tolerance alfalfa cells that identifies salt-inducible root-specific transcripts. J Plant Physiol 1994, 144:222-228.

26. Choi DW, Song JY, Kwon YM, Kim SG: Characterization of cDNA encoding a proline-rich $14 \mathrm{kDa}$ protein in developing cortical cells of the roots of bean (Phaseolus vulgaris) seedlings. Plant Mol Biol 1996, 30:973-982.

27. Ebener W, Fowler TJ, Suzuki H, Shaver J, Tierney ML: Expression of DcPRP1 is linked to carrot storage root formation and is induced by wounding and auxin treatment. Plant Physiol 1993, 101:259-265.

28. Xu Y, Buchholz WG, Derose RT, Hall TC: Characterization of a rice gene family encoding root-specific proteins. Plant Mol Biol 1995, 27:237-248.

29. Ye ZH, Varner JE: Tissue-specific expression of cell wall proteins in developing soybean tissues. Plant Cell 1991, 3:23-37.

30. Suzuki H, Fowler TJ, Tierney ML: Deletion analysis and localization of SbPRP1, a soybean cell wall protein gene, in roots of transgenic tobacco and cowpea. Plant Mol Biol 1993, 21:109-119.

31. Hong JC, Nagao RT, Key JL: Developmentally regulated expression of soybean proline-rich cell wall protein genes. Plant Cell 1989, 1:937-943.

32. Xu WL, Zhang DJ, Wu YF, Qin LX, Huang GQ, Li J, Li L, Li XB: Cotton PRP5 gene encoding a proline-rich protein is involved in fiber development. Plant Mol Biol 2013, 82:353-365.

33. Wyatt RE, Nagao RT, Key JL: Patterns of soybean proline-rich protein gene expression. Plant Cell 1992, 4:99-110.

34. Munoz FJ, Dopico B, Labrador E: A cDNA encoding a proline-rich protein from Cier arietinum. Changes in expression during development and abiotic stresses. Plant Physiol 1998, 102:582-590.

35. Xu WL, Huang GQ, Wang XL, Wang H, Li XB: Molecular characterization and expression analysis of five novel genes encoding proline-rich proteins in cotton (Gossypium hirsutum). Prog Biochemistry Biophysics 2007, 34:509-517

36. He CY, Zhang JS, Chen SY: A soybean gene encoding a proline-rich protein is regulated by salicylic acid, an endogenous circadian rhythm and by various stresses. Theor Appl Genet 2002, 104:1125-1131.

37. Tierney ML, Wiechert J, Pluymers D: Analysis of the expression of extension and p33-related cell wall proteins in carrot and soybean Mol Gen Genet 1988, 211:393-399.

38. Sheng J, D'Ovidio R, Mehdy MC: Negative and positive regulation of a novel proline-rich protein mRNA by fungal elicitor and wounding Plant J 1991, 1:345-354.

39. Marcus A, Greenberg J, Averyhart FV: Repetitive proline rich proteins in the extracellular matrix of the plant cell. Physiol Plant 1991, 81:273-279.

40. Fowler TJ, Bernhardt C, Tierney ML: Characterization and expression of four proline-rich cell wall protein genes in Arabidopsis encoding two distinct subsets of multiple domain proteins. Plant Physiol 1999 121:1081-1091.

41. Bernhardt C, Tierney ML: Expression of AtPRP3, a proline-rich structura cell wall protein from Arabidopsis, is regulated by cell-type-specific developmental pathways involved in root hair formation. Plant Physiol 2000, 122:705-714

42. Gothandam KM, Nalini E, Karthikeyan S, Shin JS: OsPRP3, a flower specific proline-rich protein of rice, determines extracellular matrix structure of floral organs and its overexpression confers cold-tolerance. Plant Mol Biol 2010, 72:125-135. 
43. Wu X, Mao A, Wang R, Wang T, Song Y, Tong Z: Molecular characterization of OsPRP1 from rice, which is expressed preferentially in anthers. Chin Sci Bull 2003, 48:2458-2465.

44. Qin LX, Zhang DJ, Huang GQ, Li L, Li J, Gong SY, Li XB, Xu WL: Cotton GhHyPRP3 encoding a hybrid proline-rich protein is stress inducible and its overexpression in Arabidopsis enhances germination under cold temperature and high salinity stress conditions. Acta Physiol Plant 2013, 35:1531-1542.

45. Winicov I, Valliyodan B, Xue LR, Hoober JK: The MsPRP2 promoter enables strong heterologous gene expression in a root-specific manner and is enhanced by overexpression of Alfin 1. Planta 2004, 219:925-935.

46. Deutch CE, Winicov l: Post-transcriptional regulation of a salt-inducible alfalfa gene encoding a putative chimeric proline-rich cell wall protein. Plant Mol Biol 1995, 27:411-418.

47. Higo K, Ugawa Y, Iwamoto M, Korenaga T: Plant cis-acting regulatory DNA element (PLACE) database. Nucleic Acids Res 1999, 27:297-300.

48. Lescot M, De'hais $P$, Thiijs $G$, Marchal $K$, Moreau $Y$, Van de Peer $Y$, Rouz $P$, Rombauts S: PlantCARE, a database of plant cis-acting regulatory elements and a portal to tools for in silico analysis of promoter sequences. Nucleic Acids Res 2002, 30:325-327.

49. Clough SJ, Bent AF: Floral dip: a simplified method for Agrobacterium mediated transformation of Arabidopsis thaliana. Plant J 1998, 16:735-743.

50. Cao D, Hou W, Liu W, Yao W, Wu C, Liu X, Han T: Overexpression of TaNHX2 enhances salt tolerance of 'composite' and whole transgenic soybean plants. Plant Cell Tissue Organ Culture 2011, 107:541-552.

51. Jefferson RA: Assaying chimeric genes in plants: the GUS gene fusion system. Plant Mol Biol Report 1987, 5:387-405.

52. Bradford MM: A rapid and sensitive method for the quantification of microgram quantities of protein utilizing the principle of protein-dye binding. Anal Biochem 1976, 72:248-254.

doi:10.1186/s12870-014-0245-z

Cite this article as: Chen et al:: GmPRP2 promoter drives root-preferential expression in transgenic Arabidopsis and soybean hairy roots. BMC Plant Biology 2014 14:245

\section{Submit your next manuscript to BioMed Central and take full advantage of:}

- Convenient online submission

- Thorough peer review

- No space constraints or color figure charges

- Immediate publication on acceptance

- Inclusion in PubMed, CAS, Scopus and Google Scholar

- Research which is freely available for redistribution 